\title{
DEVELOPMENT OF AN OXIDATION-RESISTANT HIGH-STRENGTH SIXTH- GENERATION SINGLE-CRYSTAL SUPERALLOY TMS-238
}

\author{
Kyoko Kawagishi ${ }^{1}$, An-Chou Yeh ${ }^{2,3}$, Tadaharu Yokokawa ${ }^{1}$, Toshiharu Kobayashi ${ }^{2}$, Yutaka Koizumi ${ }^{2}$ and Hiroshi Harada ${ }^{2}$ \\ ${ }^{1}$ High Temperature Materials Unit, Environment and Energy Materials Division, National Institute for Materials Science, 1-2-1 Sengen, \\ Tsukuba, Ibaraki, 305-0047, Japan \\ ${ }^{2}$ Environment and Energy Materials Division, National Institute for Materials Science, 1-2-1 Sengen, Tsukuba, Ibaraki, 305-0047, Japan \\ ${ }^{3}$ Current affiliation: Materials Science and Engineering Department, National Tsing Hua University, Taiwan (R.O.C.)
}

Keywords: Single Crystal superalloy; $6^{\text {th }}$ generation, Creep property, Environmental property

\begin{abstract}
For jet engines to meet the ever-increasing demands of ecological compatibility, the compositions of Ni-base single-crystal superalloys have continuously evolved to cope with the increase in turbine entry temperature (TET) owing to the design that improve the thermodynamic efficiency of gas turbine engines. Over the past decade, the addition of Ru has been one of the main subjects of focus to enhance the temperature capability and contribute to the development of new generations of single-crystal superalloys. This paper reposts one of the latest Ru-bearing 6th generation superalloys developed by the National Institute for Materials Science (NIMS), TMS-238. TMS-238 is a promising candidate alloy for future turbine blade applications because it exhibits excellent and well-balanced mechanical and environmental properties.
\end{abstract}

\section{Introduction}

Ni-base single-crystal superalloys have excellent hightemperature properties, and advances in the temperature capability of these materials have led to an increase in the efficiency of jet engines and gas turbines. $4^{\text {th }}$ generation $\mathrm{Ni}$-base superalloys contain 2-3 wt\% $\mathrm{Ru}$, which hinders the precipitation of topologically close packed (TCP) phases [1] and improves the high-temperature microstructure stability [2-4]. $4^{\text {th }}$ generation superalloys have achieved temperature capabilities $30^{\circ} \mathrm{C}$ higher on average than those of the previous generation superalloys in terms of high-temperature creep strength. $5^{\text {th }}$ generation superalloys have been invented by the optimization of alloying compositions, and the content of Ru has increased to 5-6wt\%; the lattice misfit between the $\gamma$ and the $\gamma^{\prime}$ phases has been controlled to balance the interfacial strengthening and coherency, and the dislocation network at the interface of the $\gamma$ and the $\gamma^{\prime}$ phases has become finer than that of $4^{\text {th }}$ generation superalloys in order to inhibit dislocation migration under stress. Thus, the hightemperature creep resistance of $5^{\text {th }}$ generation superalloys is better than that of $4^{\text {th }}$ generation superalloys [5].

However, these $4^{\text {th }}$ and $5^{\text {th }}$ generations of superalloys are likely to have lower resistance against oxidation than the previous generations owing to the higher content of refractory elements such as Mo, Re and Ru [6, 7]. These refractory-based oxide species have relatively higher vapor pressures and can disrupt the continuity of protective $\mathrm{Al}_{2} \mathrm{O}_{3}$ formed on the surface during thermal exposure. To make $4^{\text {th }}$ and $5^{\text {th }}$ generation superalloys commercially viable, an improvement in oxidation resistance is imperative. In this study, a $6^{\text {th }}$ generation superalloy, TMS-238, which exhibits both high-temperature creep strength and improved oxidation resistance, has been developed. The alloy design procedure involves utilizing the composition of TMS-196 [8] as a base to optimize the alloy chemistry so as to improve the oxidation resistance and creep strength. High-temperature properties such as creep, oxidation and hot-corrosion resistances have been evaluated for this new superalloy; the experimental results have been compared with those of a $2^{\text {nd }}$ generation superalloy CMSX-4 and a $4^{\text {th }}$ generation superalloy MX4/PWA1497.

\section{Experimental Procedure}

TMS-138A, TMS-196 and TMS-238 were designed by using the Alloy Design Program [9] developed by NIMS. TMS-138A [10] is a $4^{\text {th }}$ generation superalloy containing $5.8 \mathrm{wt} \%$ Re and $3.6 \mathrm{wt} \%$ $\mathrm{Ru}$. TMS-196 is a $5^{\text {th }}$ generation superalloy containing higher content of Re and $\mathrm{Ru}(6.4 \mathrm{wt} \% \mathrm{Re}$ and $5.0 \mathrm{wt} \% \mathrm{Ru}$ ) to realize better mechanical properties than TMS-138A and to improve the oxidation properties by adding Cr. TMS-238 was designed to have mechanical properties similar to TMS-196 but improved oxidation and hot-corrosion resistances. The Mo and $\mathrm{W}$ contents were reduced and the Co and Ta contents were increased. The compositions of alloys used in this study are shown in Table 1. The single-crystal samples used for our experiments were vacuum-induction melted and fabricated using a standard directional solidification casting furnace. Materials were supplied as $10-\mathrm{mm}$ cylindrical bars with orientations within 10 degrees of the [001] orientation. Then samples were solution heat treated and aged with no residual eutectics and no visible TCP phases in the microstructures.

Tensile specimens of $4 \mathrm{~mm}$ in diameter and $22 \mathrm{~mm}$ in gauge length were machined from the heat-treated samples, and tensile tests were conducted at $400^{\circ} \mathrm{C}$ and $750^{\circ} \mathrm{C}$. Tensile creep-upture tests were also conducted on heat-treated samples; specimens were machined into standard creep specimens and tested along the [001] direction to rupture under the following conditions: $800^{\circ} \mathrm{C} / 735 \mathrm{MPa}, 900^{\circ} \mathrm{C} / 392 \mathrm{MPa}, 1000^{\circ} \mathrm{C} / 245 \mathrm{MPa}$ and $1100^{\circ} \mathrm{C} / 137 \mathrm{MPa}$.

High-temperature cyclic oxidation tests were conducted at $1100^{\circ} \mathrm{C}$ in air for $1 \mathrm{~h}$ per cycle. Specimens were machined to $9 \mathrm{~mm}$ in diameter and $5 \mathrm{~mm}$ in thickness, and the surfaces were finished with 600 -grade SiC paper polishing followed by cleaning with acetone. The change in weight of each specimen was measured at the end of each cycle. The hot-corrosion property was also investigated. Specimens measuring $9 \mathrm{~mm}$ in diameter by $5 \mathrm{~mm}$ in thickness were soaked in $75 \% \mathrm{Na}_{2} \mathrm{SO}_{4}+25 \% \mathrm{NaCl}$ molten salt at 
Table 1. Nominal compositions (wt $\%$, Ni bal.).

\begin{tabular}{l|cccccccccc}
\hline \multicolumn{1}{c|}{ Alloy } & Co & Cr & Mo & W & Al & Ti & Ta & Hf & Re & Ru \\
\hline CMSX-4 & 9.6 & 6.4 & 0.6 & 6.4 & 5.6 & 1.0 & 6.5 & 0.1 & 3.0 & 0.0 \\
MX-4/PWA1497 & 16.5 & 2.0 & 2.0 & 6.0 & 5.55 & 0.0 & 8.25 & 0.15 & 5.95 & 3.0 \\
TMS-138A & 5.8 & 3.2 & 2.8 & 5.6 & 5.7 & 0.0 & 5.6 & 0.1 & 5.8 & 3.6 \\
TMS-196 & 5.6 & 4.6 & 2.4 & 5.0 & 5.6 & 0.0 & 5.6 & 0.1 & 6.4 & 5.0 \\
TMS-238 & 6.5 & 4.6 & 1.1 & 4.0 & 5.9 & 0.0 & 7.6 & 0.1 & 6.4 & 5.0 \\
\hline
\end{tabular}

Table 2. $0.2 \%$ yield stress and UTS at $400^{\circ} \mathrm{C}$ and $750^{\circ} \mathrm{C}$ (MPa).

\begin{tabular}{c|cccc}
\hline \multirow{2}{*}{ Alloy } & \multicolumn{2}{|c}{$400^{\circ} \mathrm{C}$} & \multicolumn{2}{c}{$750^{\circ} \mathrm{C}$} \\
\cline { 2 - 5 } & $0.2 \%$ yield & UTS & $0.2 \%$ yield & UTS \\
\hline CMSX-4 & 860 & 950 & 950 & 1150 \\
TMS-138A & 830 & 906 & 868 & 1241 \\
TMS-196 & 879 & 1214 & 845 & 1308 \\
TMS-238 & 925 & 1373 & 1041 & 1348 \\
\hline
\end{tabular}

$900^{\circ} \mathrm{C}$ for $20 \mathrm{~h}$. Metal losses in thickness were calculated from weight losses after this 20 -h soak.

\section{Results and Analysis}

In this section, the experimental results are presented and analyzed. Table 2 shows the results of tensile tests conducted at $400^{\circ} \mathrm{C}$ and $750^{\circ} \mathrm{C}$. The $0.2 \%$ yield stress and UTS of TMS- $138 \mathrm{~A}$ are comparable with those of CMSX-4 at both temperatures; TMS-196 shows some improvement and TMS-238 exhibits the highest yield stress and UTS. Figure 1 shows creep performances of CMSX-4, MX-4/PWA1497, TMS-138A, TMS-196 and TMS238 with respect to the Larson-Miller Parameter. The creeprupture lives of TMS-238 are comparable to those of TMS-138A and TMS-196 at $800^{\circ} \mathrm{C} / 735 \mathrm{MPa}, 900^{\circ} \mathrm{C} / 392 \mathrm{MPa}$, and $1000^{\circ} \mathrm{C} / 245 \mathrm{MPa}$. Interestingly, the creep-rupture life of TMS238 is significantly greater than that of TMS-138A and TMS-196 at $1100^{\circ} \mathrm{C} / 137 \mathrm{MPa}$, although the content of Mo in TMS-238 is less than that in TMS-138A and TMS-196. All the TMS alloys perform better than CMSX-4, and exhibits a performance similarly to MX-4/PWA1497 at $900^{\circ} \mathrm{C} / 392 \mathrm{MPa}$. The advantage of TMS alloys is much more pronounced at lower temperatures/higher stress and higher temperatures/lower stress conditions. Microstructure observations of crept specimens at $1100^{\circ} \mathrm{C} / 137 \mathrm{MPa}$ are shown in Fig. 2. Finest lamellar structure found in TMS-238 attributed to its excellent creep property.
The oxidation property was investigated and is shown in Fig. 3. TMS-196 showed an improvement over TMS-138A and has excellent oxidation resistance compared with other $4^{\text {th }}$ and $5^{\text {th }}$ generation superalloys [11]: however, it shows a large decrease in mass in the cyclic oxidation test because of scale spallation, and the oxidation resistance is still inferior to CMSX-4. CMSX-4 shows a relatively stable profile but a slight decrease in mass is found after 50 cycles. Interestingly, TMS-238 shows a constant and gentle increase in mass change until 500 cycles and above. Cross-section images of oxide scales after $1 \mathrm{~h}$ of isothermal oxidation at $1100^{\circ} \mathrm{C}$ were observed and are shown in Fig. 4. TMS$138 \mathrm{~A}$ forms a very thick $\mathrm{NiO}$ layer at the surface, and spinel layer and thick internal $\mathrm{Al}_{2} \mathrm{O}_{3}$ dispersion zones are formed beneath the NiO layer. CMSX-4, TMS-196 and TMS-238 show a similar oxide structure consisting of $\mathrm{NiO}$, complex oxides and a protective $\mathrm{Al}_{2} \mathrm{O}_{3}$ layer. The scale thicknesses of CMSX-4 and TMS-238 are almost equal and thinner than that of TMS-196. Kirkendall voids were found beneath the $\mathrm{Al}_{2} \mathrm{O}_{3}$ layer in TMS-196 and TMS-238. From these observations, it is clear that TMS-238 has superior oxidation resistance compared with CMSX-4 at $1100^{\circ} \mathrm{C}$, although it contains less $\mathrm{Cr}$ and more Mo and $\mathrm{Ru}$ than CMSX-4. It is possible that the higher Ta and lower W content may be beneficial in improving the oxidation resistance of TMS238. 


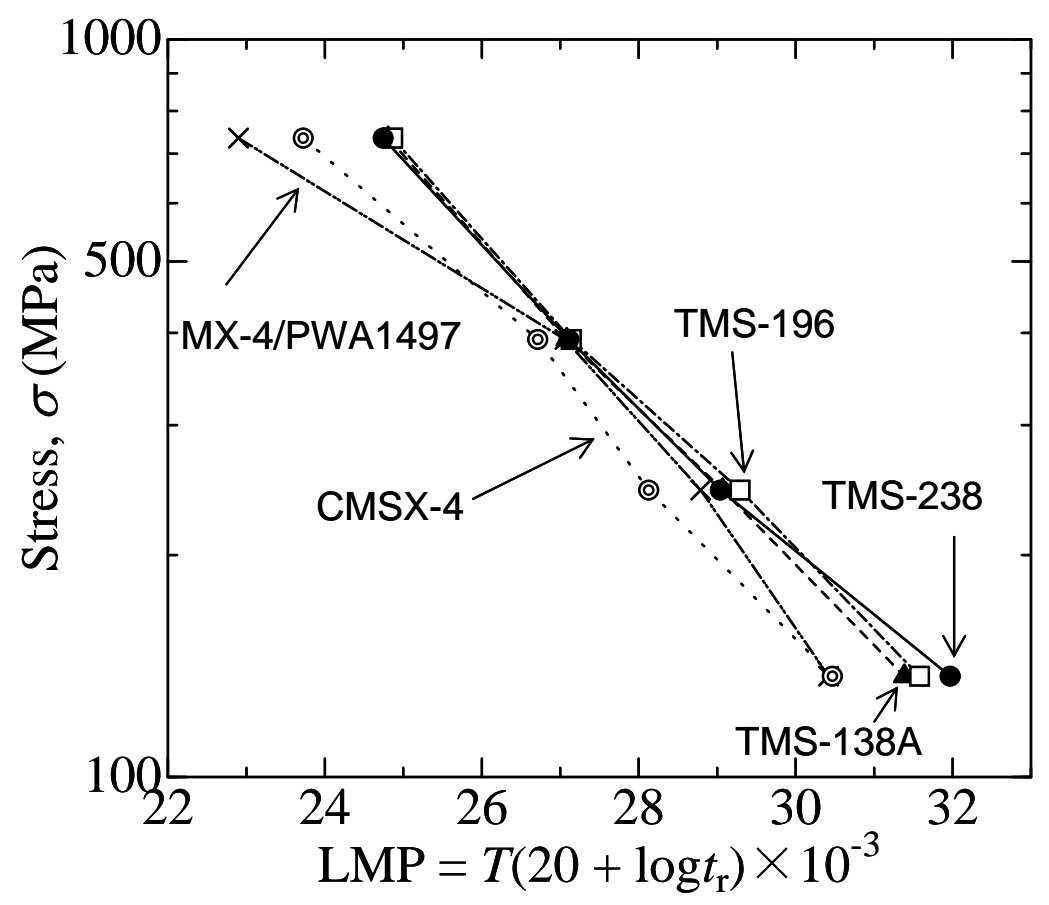

Figure 1. Larson-Miller diagram of creep properties of the investigated alloys.
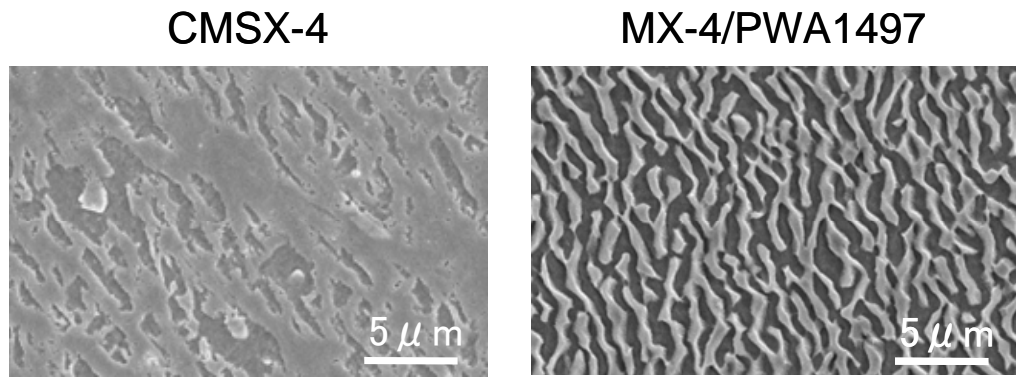

TMS-138A
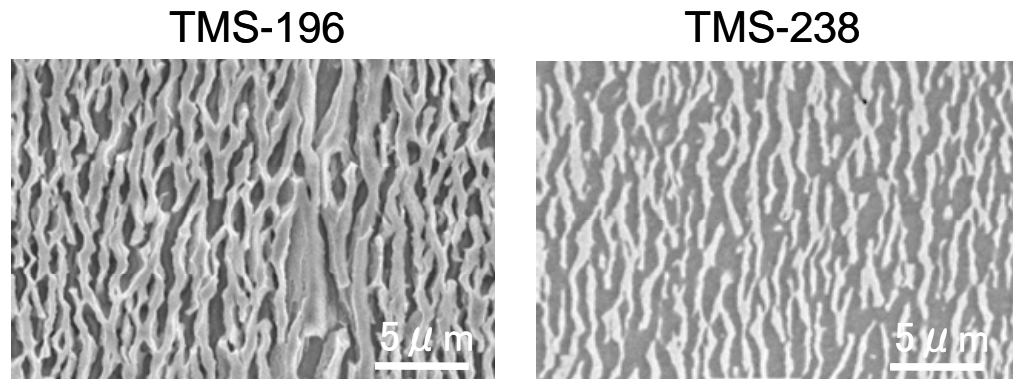

Figure $2.1100^{\circ} \mathrm{C} / 137 \mathrm{MPa}$ crept microstructures of the investigated alloys. 


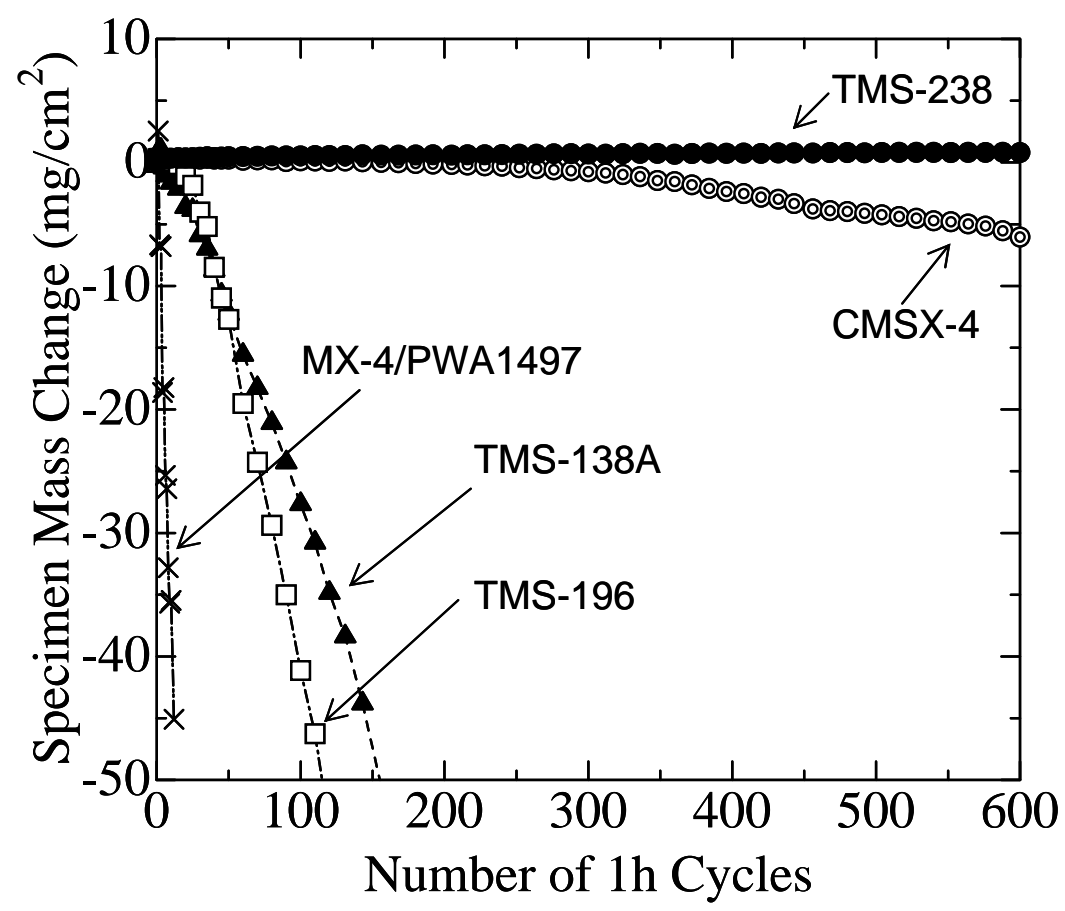

Figure 3. Results of $1100^{\circ} \mathrm{C}$ cyclic oxidation tests.
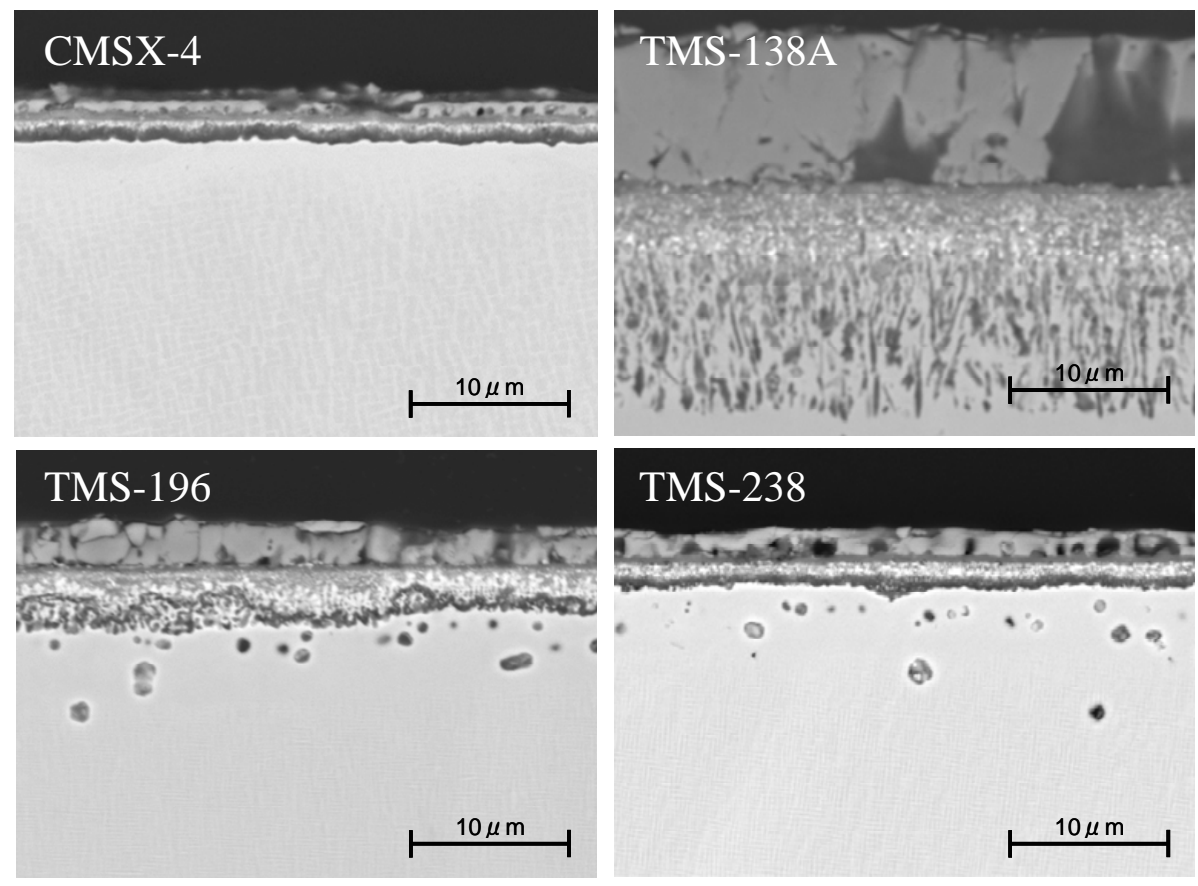

$\theta$

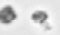

Figure 4. Microstructures after $1 \mathrm{~h}$ exposure at $1100^{\circ} \mathrm{C}$. 


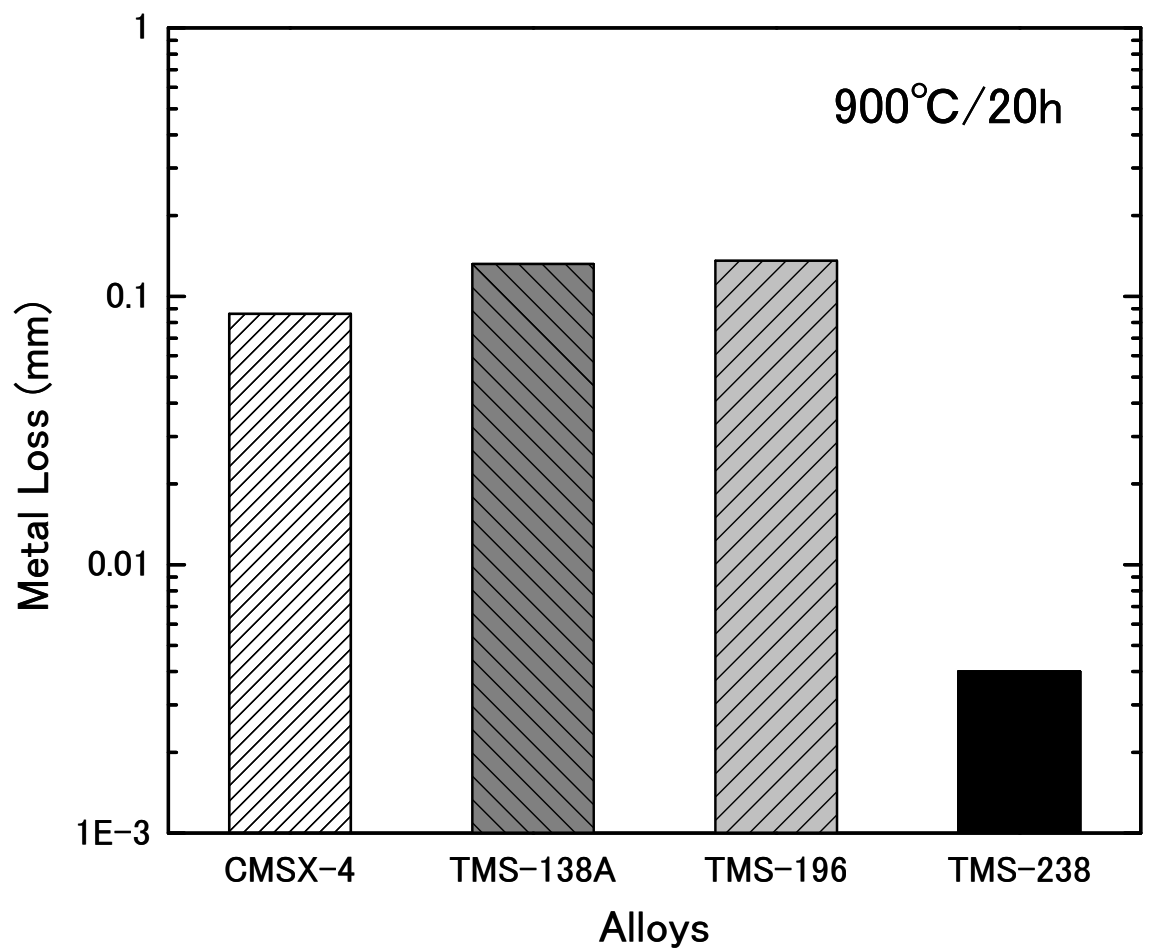

Figure 5. Results of hot- ${ }^{-}$corrosion tests.

Hot-corrosion resistance was evaluated by a crucible test, and Fig. 5 shows the metal losses of CMSX-4, TMS-196 and TMS-238 after $20 \mathrm{~h}$ of soaking. TMS-238 had by far the lowest metal loss; hence, this alloy exhibits the best hot-corrosion resistance. It is likely that a lower Mo content and a higher Re content are responsible for this excellent property. Further investigation is required to elucidate the underlying mechanisms.

Figure 6 shows the relationship between creep property and the oxidation resistance. The vertical axis is the oxidation resistance at $1100^{\circ} \mathrm{C}$, which was originally defined as including the factors of isothermal mass increase and cyclic mass decrease, and it is expressed as

$$
\text { Oxidation Resistance }=\log \left(\frac{1}{w_{1}} \times \frac{1}{\left|w_{50}-w_{1}\right|}\right)
$$

where $w_{1}$ is mass gain after the $1^{\text {st }}$ cycle and $w_{50}-w_{1}$ is the mass change from the $1^{\text {st }}$ cycle to the $50^{\text {th }}$ cycle in a $1100^{\circ} \mathrm{C}$ cyclic oxidation test. In this equation, $1 / w_{1}$ is the isothermal oxidation resistance and a $1 /\left|w_{50}-w_{1}\right|$ is the cyclic oxidation resistance. A larger value means better durability in both factors, and so the total oxidation resistance is expressed as the increase in the value in the vertical axis in Fig. 6. The horizontal axis indicates the rupture life (h) in the creep test at $1100^{\circ} \mathrm{C} / 137 \mathrm{MPa}$. The open squares, diamonds, triangles and inverted triangles are symbols representing commercial $1^{\text {st }}, 2^{\text {nd }}, 3^{\text {rd }}$ and $4^{\text {th }}$ generation superalloys. The solid inverted triangle, solid circle and solid double circle stand for NIMS $4^{\text {th }}, 5^{\text {th }}$ and $6^{\text {th }}$ generation superalloys. Superalloys were developed focusing on only their mechanical properties up to $4^{\text {th }}$ generation, as shown by the gray arrows in the figure. However, the solid circle and the solid double circle in Fig. 6 show that superalloys with good oxidation resistance and mechanical properties are being developed owing to the recent efforts to improve the oxidation resistance of these alloys. It is evident that TMS-238 has excellent mechanical and environmental properties and that these are in good balance with each other.

\section{Discussion}

The composition of alloys influence phase stability, $\gamma / \gamma^{\prime}$ lattice misfit, microstructural evolutions, and oxides formations, which in turn affect surface stability and mechanical properties. The average $\gamma^{\prime}$ size of a conventional superalloy such as CMSX-4 is $0.5 \mu \mathrm{m}$. The lower $\gamma^{\prime}$ solvus temperature and higher Re content in TMS-238 limits the growth of $\gamma^{\prime}$ and slows the rate of diffusion after solution and aging heat treatment. With the addition of $\mathrm{Ru}$, TMS alloys exhibit greater microstructural stability than CMSX-4, although TMS alloys contain a higher amount of refractory elements. This microstructure instability can be attributed to the higher $\mathrm{Re}$ and $\mathrm{Cr}$ contents, because both elements are very potent 


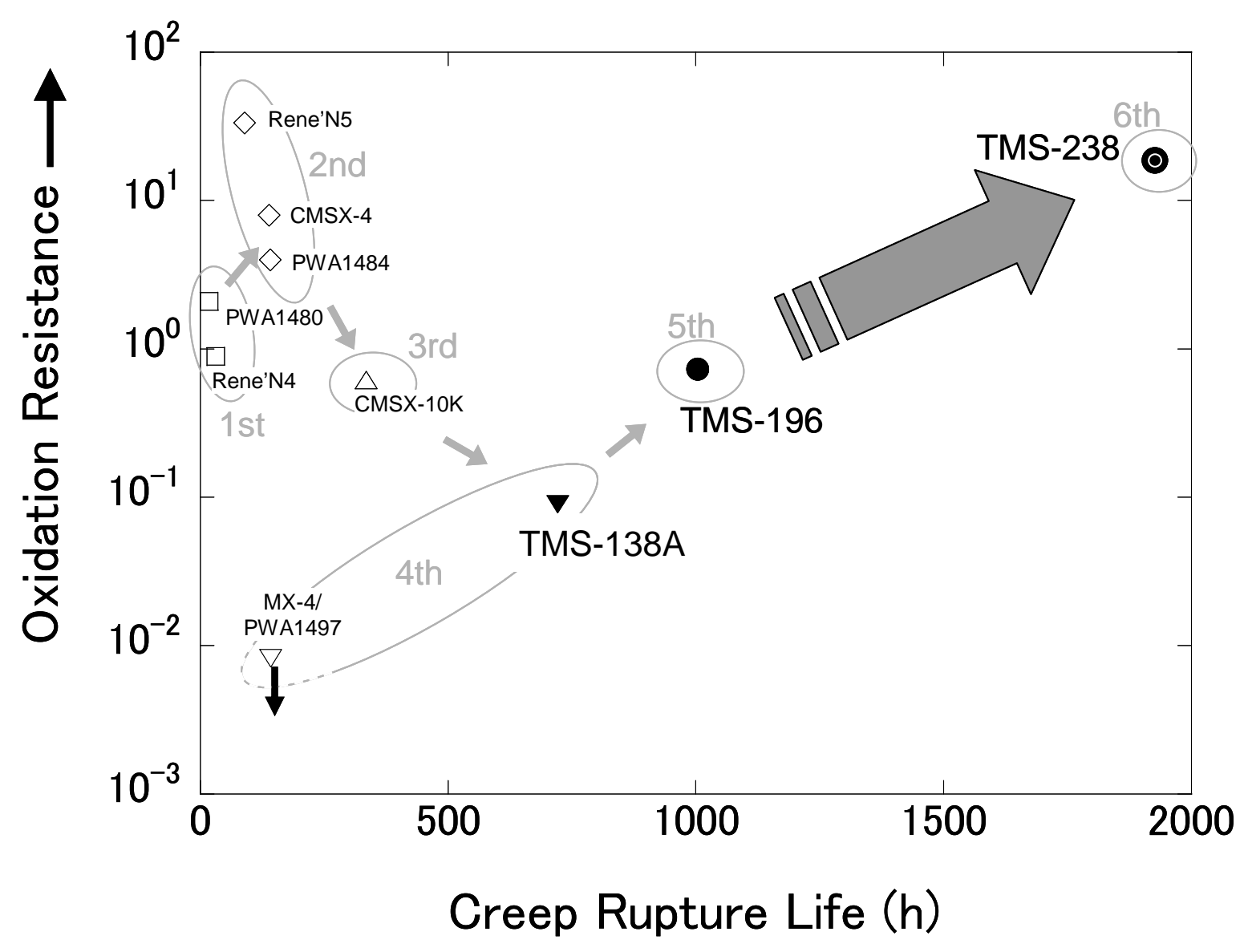

Figure 6. Graph showing comparisons among alloys in terms of a combination of $1100^{\circ} \mathrm{C} / 137 \mathrm{MPa}$ creep and $1100^{\circ} \mathrm{C}$ oxidation resistances.

in forming TCP phases; Re tends to heavily segregate into the dendritic core, in which TCP precipitates can first be observed. However, further reducing the residual Re segregation by added solution heat treatment can reduce the tendency for TCP and $\delta$ phase formation in TMS alloys. A previous study [10] suggests that a high $\mathrm{Ru}$ content in superalloys may not necessary imply greater microstructural stability, because the overall chemical composition needs to be balanced to prevent precipitations of both TCP and $\delta$ phases.

The differences between the creep behaviors of CMSX-4 and TMS alloys demonstrate the important role of $\gamma / \gamma^{\prime}$ lattice misfit in influencing deformation mechanisms. The $\gamma / \gamma^{\prime}$ lattice misfit of TMS alloys compared with that of CMSX-4 is more negative owing to the higher amounts of $\mathrm{Re}$ and $\mathrm{Ru}$ that partition preferentially into the $\gamma$ phase and expand the lattice parameter of $\gamma$. Increasing the $\gamma / \gamma^{\prime}$ lattice misfit toward the negative not only enhances the rafting kinetics but also refines the dislocation network at the $\gamma / \gamma^{\prime}$ interface during high-temperature creep. Although the formation of a raft is beneficial against creep in a high-temperature/low-stress condition, the rafted microstructure can be detrimental under intermediate-temperature/intermediatestress creep condition [10].
It is very interesting to note that TMS-238 exhibits both strong creep and oxidation resistances, and the alloy composition has a higher Ta contents; the Mo content is relatively low to minimize the degradation in oxidation resistance typically observed in this class of superalloys that contain large amount of refractory elements. Furthermore, TMS-238 has been designed to exhibit a slightly smaller lattice misfit between the $\gamma$ and $\gamma^{\prime}$ phases compared with TMS-196, so as to retain a greater coherency of the microstructure after heat treatment. For TMS-238, the combination of greater microstructure stability and an optimized refractory content result in an alloy exhibiting impressive resistances against creep, hot corrosion and oxidation.

\section{Conclusions}

Our recent work at NIMS shows that advanced $5^{\text {th }}$ generation superalloys can be developed having excellent resistance against high-temperature creep, oxidation and corrosion. This paper demonstrates that the TMS-238 superalloy is a promising candidate alloy for turbine blade applications, because this material possesses a balance of the properties desired by gas turbine engine manufacturers to improve engine efficiency. We 
believe that our $6^{\text {th }}$ generation single-crystal superalloy TMS-238 has the most excellent and well-balanced mechanical and environmental properties among the existing superalloys.

\section{Acknowledgements}

The authors acknowledge the financial support partly provided by Rolls-Royce plc for this research.

\section{References}

1. A. Sato, Y. Koizumi, T. Kobayashi, T. Yokokawa, H. Harada and H. Imai, "TTT Diagram for TCP Phases Precipitations of $4^{\text {th }}$ Generation Ni-Base Superalloys”, $J$ Japan Inst Metals, 68 (2004), pp. 507-510.

2. K. O’Hara, W.S. Walston, E.W. Ross and R. Darolia, U.S. Patent 5,482,789, "Nickel Base Superalloy and Article", 1996.

3. Y. Koizumi, T. Kobayashi, T. Yokokawa, H. Harada, Y. Aoki, M. Arai, S. Masaki and K. Chikugo, "Development of $4^{\text {th }}$ Generation Single Crystal Superalloys”, Proceedings (2nd International Symposium on High Temperature Materials, Tsukuba, Japan, 31 May - 2 June 2001), pp. 30 31.

4. J. X. Zhang, T. Murakumo, Y. Koizumi, T. Kobayashi, H. Harada and S. Masaki, "Interfacial Dislocation Networks Strengthening a Fourth-Generation Single-Crystal TMS138 Superalloy”, Metall. Mater. Trans. A, 33A (2002), pp. 3741-3746.

5. Y. Koizumi, T. Kobayashi, T. Yokokawa, J. X. Zhang, M. Osawa, H. Harada, Y Aoki and M. Arai, "Development of Next-Generation Ni-Base Single Crystal Superalloys", Superalloys 2004, (TMS, 2004), pp. 35-43.

6. S. Walston, A. Cetel, R. MacKay, K. O’Hara, D. Duhl and R. Dreshfield, "Joint Development of a Fourth Generation Single Crystal Superalloy”, Superalloys 2004, (TMS, 2004), pp. 15-24.

7. K. Kawagishi, A. Sato, T. Kobayashi and H. Harada, "Effect of Alloying Elements on the Oxidation Resistance of 4th Generation Ni-base Single-crystal Superalloys", $J$. Japan Inst. Metals, 69 (2005), pp. 249-252.

8. A. Sato, H. Harada, A. C. Yeh, K. Kawagishi, T. Kobayashi, Y. Koizumi, T. Yokokawa and J. X. Zhang, “A 5th Generation SC Superalloy with Balanced High Temperature Properties and Processability”, Superalloys 2008, (TMS, 2008), pp.131-138.

9. H. Harada, K. Ohno, T. Yamagata, T. Yokokawa and M. Yamazaki, "Phase Calculation and Its Use in Alloy Design Program for Nickel-Base Superalloys", Superalloys1988. (TMS, 1988), pp. 733-742.

10. A. C. Yeh, A. Sato, T. Kobayashi and H. Harada, "On the Creep and Phase Stability of Advanced Ni-base Single Crystal Superalloys”, Materials Science and Engineering A, 490 (2008), pp. 445-451.

11. K. Kawagishi, A. Sato, H. Harada, A. C. Yeh, Y. Koizumi, and T. Kobayashi, "Oxidation Resistant Ru Containing Ni Base Single Crystal Superalloys", Materials Science and Technology, 25 (2009), pp. 271-275. 